\title{
openheart Decreased magnesium status may mediate the increased cardiovascular risk associated with calcium supplementation
}

\author{
James J DiNicolantonio, ${ }^{1}$ Mark F McCarty, ${ }^{2}$ James H O’Keefe ${ }^{1}$
}

\section{To cite:}

DiNicolantonio JJ, McCarty MF, O'KeefeJH.Decreasedmagnesium status may mediate the increased cardiovascular risk associated with calcium supplementation. Open Heart 2017;7:e000617. doi:10.1136/ openhrt-2017-000617

Accepted 25 April 2017

\section{CrossMark}

${ }^{1}$ Saint Luke's Mid America Heart Institute, Kansas City, Missouri, USA

${ }^{2}$ Catalytic Longevity, Carlsbad, California, USA

Correspondence to James J DiNicolantonio; jjdinicol@gmail.com

\section{CAN SUPPLEMENTAL CALCIUM INCREASE CARDIOVASCULAR RISK?}

A meta-analyses of randomised controlled studies of calcium supplementation (some including concurrent modest intakes of vitamin $\mathrm{D}$ ) has observed a modest increase in risk for vascular events in the calcium-supplemented subjects. ${ }^{1}$ Some recent observational epidemiology in prospective cohorts has also linked supplemental calcium to increased vascular risk..$^{2-4}$ Yet, rather perplexingly, relatively high dietary intakes of calcium have been associated with cardiovascular protection, or a neutral outcome in this regard. ${ }^{2356}$ Moreover, there are theoretical grounds for expecting that superior calcium nutrition could be protective for vascular health. High-calcium diets decrease secretion of parathyroid hormone; even mild secondary hyperparathyroidism, common in the elderly, is suspected to increase vascular risk. ${ }^{78} \mathrm{~A}$ high calcium intake also tends to suppress absorption of dietary phosphate by forming an insoluble complex with it; emerging data suggest that high phosphate intakes may increase cardiovascular risk, even in those with normal renal function. ${ }^{9}$ High calcium intakes have not been found to correlate with increased risk for vascular calcification. ${ }^{10}$ The acute vascular impact of the modest rise in serum calcium following a bolus oral dose of calcium citrate has been studied; relative to placebo, arterial stiffness declined and myocardial perfusion increased in the calcium group. ${ }^{11}$ However, the diurnal decline in blood pressure was not as high in calcium-supplemented subjects and a coagulation index (thromboelastography) increased. $^{12}$

What could explain the increased risk for vascular events associated specifically with calcium supplementation in some controlled studies? Even if subsequent analyses fail to confirm a net negative impact of calcium supplementation on vascular health-this issue is hotly debated and cannot be considered resolved ${ }^{5}{ }^{13-15-}$ the fact that calcium could be expected to protect the vasculature for certain reasons suggests that it must be exerting some countervailing negative effect even if its impact on vascular health is neutral.

The acute impact of bolus calcium on coagulation mechanisms, as noted above, merits further study. Also, a high calcium intake might increase secretion of reninwhich increases cardiovascular risk ${ }^{16}$ via the prohypertensive, pro-oxidative effects of angiotensin II-by suppressing renal synthesis of calcitriol. ${ }^{17}$ Only a few pertinent clinical studies are currently available in this regard, ${ }^{18}$

${ }^{19}$ however, and this prediction requires more verification in clinical studies using realistic supplemental intakes of calcium. Moreover, this explanation leaves unexplained the seeming discrepancy between the apparent cardioprotection of dietary calcium versus the potential cardiotoxicity of supplemental calcium.

Consideration should, therefore, be given to the possibility that, in some individuals, high supplemental intakes of calcium may disturb magnesium balance. ${ }^{20} \mathrm{~A}$ great deal of recent epidemiology, including meta-analyses, points to higher dietary magnesium intakes, and/or higher serum magnesium levels, as associated with reduced risk for vascular events, arrhythmias, diabetes, hypertension, metabolic syndrome, vascular calcification and mortality. ${ }^{21-41}$ Although to some degree these observations likely reflect the benefits of consuming nutrient-rich whole foods, rather than just magnesium per se, magnesium still often emerges as protective after multiple regression analyses which try to adjust for this 
effect. Moreover, short-term studies of magnesium supplementation in persons at high cardiovascular risk have often found protective effects, particularly in those with low baseline magnesium status. Notably, in patients with coronary disease, magnesium supplementation has been found to decrease ex vivo platelet-dependent thrombosis, increase flow-mediated vasodilation of the brachial artery and during exercise, increase exercise tolerance, $\mathrm{VO}_{2} \max$ and left ventricular ejection fraction. ${ }^{42-46} \mathrm{~A}$ meta-analysis of placebo-controlled studies evaluating the impact of supplemental magnesium on treated hypertensives with baseline systolic pressure $>155 \mathrm{~mm} \mathrm{Hg}$, found a mean reduction of 18.7 and $10.9 \mathrm{~mm} \mathrm{Hg}$ in systolic and diastolic pressures, respectively, with high statistical significance. ${ }^{47}$ The mechanism of the apparent benefits conferred by good magnesium status requires further study, but it is suspected that magnesium antagonises some of the proinflammatory effects of increased cytoplasmic calcium. ${ }^{20}$ ${ }^{48-52}$ Indeed, magnesium has sometimes been referred to as 'nature's physiological calcium blocker'. ${ }^{53-55}$ For example, in physiological intracellular concentrations, magnesium competes with calcium for binding to calmodulin and other 'EF-hand' calcium-binding proteins, such that magnesium-bound proteins assume an 'off' configuration..$^{52}$ The apparent ability of good magnesium status to diminish risk for vascular calcification is intriguing in light of recent epidemiology pointing to increased risk of coronary calcification in people using calcium supplements. ${ }^{404156}$ Figure 1 depicts the inverse association between total dietary magnesium intake and risk for arterial calcification. ${ }^{56}$

\section{DIETARY CALCIUM AS A DETERMINANT OF MAGNESIUM BALANCE}

In a series of magnesium balance studies conducted by Seelig about 50 years ago, she found that, in men with recommended dietary allowance (RDA)-level magnesium intakes $(6 \mathrm{mg} / \mathrm{kg} /$ day or above), increasing dietary calcium to high levels did not impair magnesium balance- consistent with more recent reports. ${ }^{20}$ ${ }^{57} 58$ However, in men with relatively low intakes, a high calcium intake did indeed decrease magnesium balance. Somewhat paradoxically, a low calcium intake also impaired magnesium availability in this group. If these observations are confirmed in women, they imply that a high supplemental intake of calcium might impair magnesium balance in the rather high proportion of the population who have relatively low magnesium intakes, reflecting high intakes of 'empty calorie' foods. However, an increased intake of calcium-rich natural foods would not necessarily have a negative impact on magnesium balance because these foods also would supply magnesium. A cup of milk can provide up to $10 \%$ of the dietary magnesium requirement, for example.

Further balance studies are needed to confirm Seelig' ${ }^{57}$ observation that a high calcium intake can decrease magnesium balance when magnesium intakes are relatively low. Calcium and magnesium are not thought to share common transport proteins in the intestinal mucosa or renal tubular epithelium, ${ }^{59} 60$ it is, therefore, not clear what the mechanistic basis for such an antagonism might be. Inhibition of magnesium absorption by high dietary calcium is a well-established phenomenon in rats. ${ }^{61}$ Brink and colleagues have

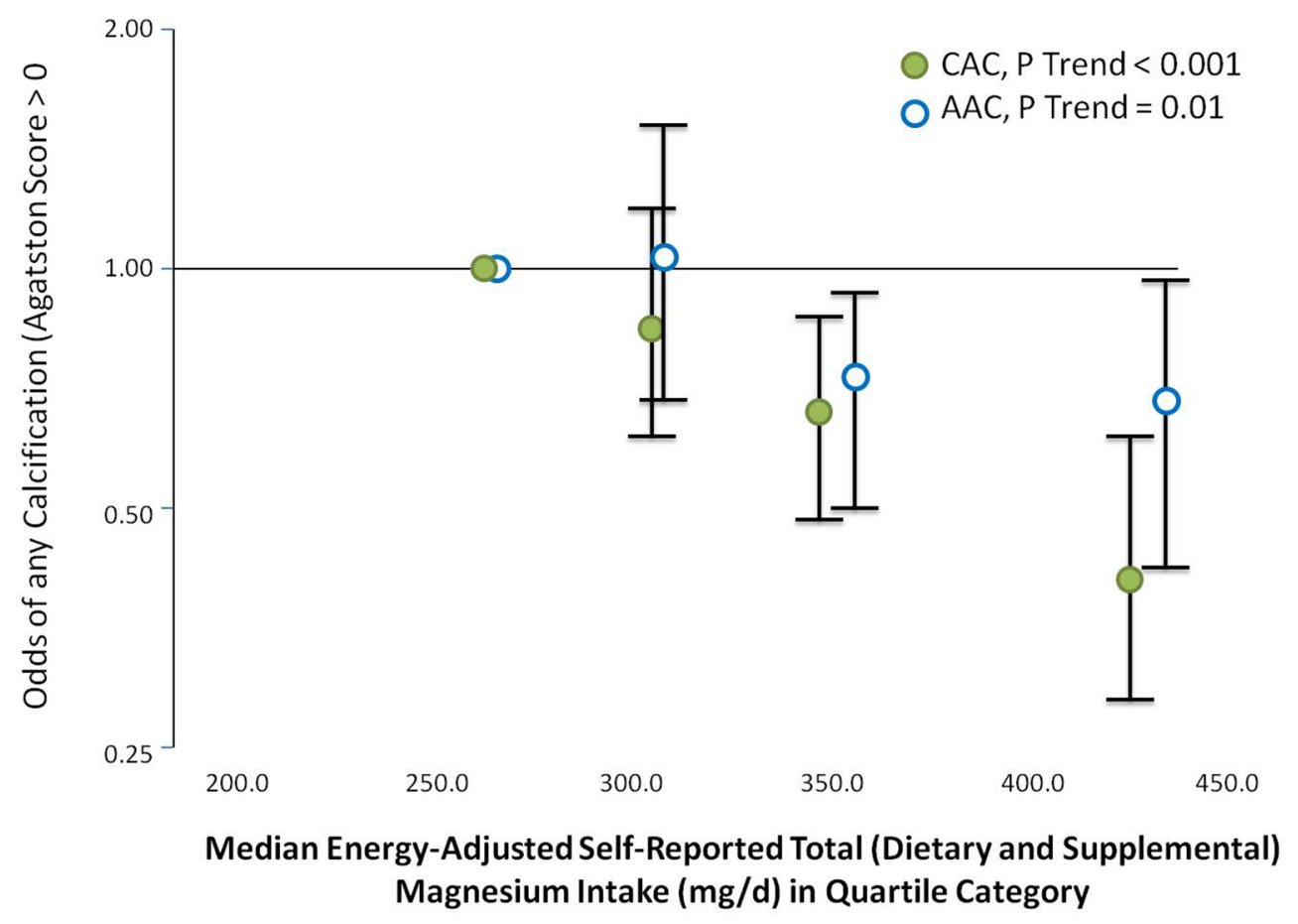

Figure 1 Adjusted odds of prevalent or high CAC and AAC according to self-reported total (dietary and supplemental) magnesium intake. Data from Hruby et al. ${ }^{56}$ 
presented evidence that this phenomenon is contingent on a concurrent sufficiently high intake of phosphate. ${ }^{62}$ These researchers show in rats that an increased intake of calcium can decrease the ileal solubility of dietary magnesium by promoting the formation of insoluble calcium/ magnesium/phosphate complexes. This phenomenon is most meaningful when the ratio of dietary phosphate to magnesium is relatively high, and Brink et $a l^{62}$ suggest that the fact that this ratio is higher in rat diets than it tends to be in humans may account for the failure of high calcium intakes to suppress magnesium balance in most clinical studies. Nonetheless, many people who consume over-refined low magnesium diets also take in a high amount of bioavailable phosphate from animal products and phosphate additives ${ }^{63}$; this could be a subset of people in whom a high supplemental intake of calcium further compromises magnesium status.

Alternatively, it has been suggested that the suppression of parathyroid hormone and/or calcitriol associated with high intakes of calcium might downregulate the efficiency of magnesium absorption. ${ }^{64}$ Although intestinal magnesium absorption is primarily paracellular, active cellular transport via TRPM6 is likely to become more physiologically important as magnesium intakes decline. ${ }^{59}$ Several studies in humans, as well as in rats, conclude that calcitriol administration can enhance intestinal absorption of magnesium; jejunal absorption of magnesium was increased in the human studies. ${ }^{61}$ ${ }^{66-71}$ The possibility that vitamin $\mathrm{D}$ receptor activation might increase expression of TRPM6 in epithelial cells derived from jejunal mucosa does not appear to have been studied to date; such a mechanism could rationalise evidence that high calcium intakes only suppress magnesium balance when magnesium intake is low and hence more dependent on active cellular transport. Homeostatically, it would make sense that calcitriol, a signal to boost calcium uptake, would concurrently boost magnesium absorption, as maintaining a balance between calcium and magnesium levels is physiologically appropriate.

\section{BALANCED SUPPLEMENTAL INTAKES OF CALCIUM AND MAGNESIUM MAY BE ADVISABLE}

If high calcium intakes in humans can indeed impair magnesium balance when magnesium intakes are low, the clear implication is that calcium, when supplemented, should be given in conjunction with a balanced dose of magnesium; some authorities recommend a 2:1 ratio of calcium to magnesium (by weight) as most appropriate, both for supplementation and the total daily intake. ${ }^{72}$ This seems appropriate considering that good magnesium status also appears to favourably impact bone structure. ${ }^{7-76}$ The concept of 'balancing' calcium and magnesium in supplements has, in fact, been the accepted wisdom in 'health food' circles for decades, owing to Seelig's research and its promulgation by popular health food pundits. However, the calcium supplements featured in pharmacies and supermarkets—where most people shop—typically feature only calcium and vitamin D. Research and promotional efforts sponsored by the dairy industry have insured that calcium is highly valued by the general public, whereas magnesium, no less crucial to health, is essentially an 'orphan nutrient', lacking the advocacy of commercial interests.

It should be noted that calcium/magnesium balance may cut both ways. In China, where the use of dairy products is low, dietary calcium/magnesium ratios tend to be much lower than in the West (1.7 vs 3). A recent analysis of prospective cohort studies in Shanghai has observed that, among people with a calcium/magnesium ratio under 1.7, an increasing intake of magnesium correlates with increased total mortality, whereas in those with a calcium/magnesium ratio above 1.7 , increases in intake of magnesium and/or calcium correlated with reduced mortality risk. ${ }^{77}$ Hence, a high supplemental intake of magnesium may be inadvisable when calcium intakes are low.

Thus, more clinical studies examining the impact of varying calcium intakes on magnesium balance in subjects with low-normal magnesium intakes are clearly needed, as is a better understanding of the molecular mechanisms, whereby calcium can both positively and negatively influence magnesium absorption and retention. Future epidemiological studies should make an effort to differentiate calcium supplementers into those who either do or do not use supplemental magnesium concurrently, and also take into consideration dietary magnesium intake. In the mean time, people (especially those consuming a relatively refined diet) who wish to supplement with calcium might be well advised to take a supplement that also includes highly bioavailable magnesium, targeting a 2:1 calcium to magnesium ratio in the overall diet.

Contributors JJD, MFM, and JHO contributed to the final manuscript.

Funding This manuscript received no specific grant from any funding agency in the public, commercial or not-for-profit sectors.

Competing interests JHO: Chief Medical Officer and Founder of CardioTabs, a nutraceutical company, have a major ownership interest in the company. CardioTabs does sell products that contain Omega-3. MFM: owner and science director of NutriGuard Research, a nutraceutical company. A few of NutriGuard's products contain calcium and/or magnesium.

Provenance and peer review Not commissioned; externally peer reviewed.

Data sharing statement № additional data are available for this paper.

Author note An earlier version of this article was previously published online at on February 2016.

Open Access This is an Open Access article distributed in accordance with the Creative Commons Attribution Non Commercial (CC BY-NC 4.0) license, which permits others to distribute, remix, adapt, build upon this work non-commercially, and license their derivative works on different terms, provided the original work is properly cited and the use is non-commercial. See: http://creativecommons.org/ licenses/by-nc/4.0/

(c) Article author(s) (or their employer(s) unless otherwise stated in the text of the article) 2017. All rights reserved. No commercial use is permitted unless otherwise expressly granted.

\section{REFERENCES}

1. Bolland MJ, Grey A, Avenell A, et al. Calcium supplements with or without vitamin D and risk of cardiovascular events: reanalysis of the 
Women's Health Initiative limited access dataset and meta-analysis. BMJ 2011;342:d2040.

2. Xiao Q, Murphy RA, Houston DK, et al. Dietary and supplemental calcium intake and cardiovascular disease mortality: the National Institutes of Health-AARP diet and health study. JAMA Intern Med 2013;173:639-46.

3. Li K, Kaaks R, Linseisen J, et al. Associations of dietary calcium intake and calcium supplementation with myocardial infarction and stroke risk and overall cardiovascular mortality in the Heidelberg cohort of the European Prospective Investigation into Cancer and Nutrition study (EPIC-Heidelberg). Heart 2012;98:920-5.

4. Anderson JJ, Kruszka B, Delaney JA, et al. Calcium intake from diet and supplements and the risk of coronary artery calcification and its progression among older adults: 10-year follow-up of the Multi-Ethnic Study of Atherosclerosis (MESA). J Am Heart Assoc 2016;5:e003815.

5. Wang L, Manson JE, Sesso HD. Calcium intake and risk of cardiovascular disease: a review of prospective studies and randomized clinical trials. Am J Cardiovasc Drugs 2012;12:105-16.

6. Chan R, Leung J, Woo J. A prospective cohort study examining the associations of dietary calcium intake with all-cause and cardiovascular mortality in older chinese community-dwelling people. PLoS One 2013;8:e80895.

7. Anderson JL, Vanwoerkom RC, Horne BD, et al. Parathyroid hormone, vitamin $\mathrm{D}$, renal dysfunction, and cardiovascular disease: dependent or independent risk factors? Am Heart J 2011;162:331-9.

8. Peiris AN, Youssef D, Grant WB. Secondary hyperparathyroidism: benign bystander or culpable contributor to adverse health outcomes? South Med J 2012;105:36-42.

9. Ellam TJ, Chico TJ. Phosphate: the new cholesterol? The role of the phosphate axis in non-uremic vascular disease. Atherosclerosis 2012;220:310-8.

10. Samelson EJ, Booth SL, Fox CS, et al. Calcium intake is not associated with increased coronary artery calcification: the Framingham Study. Am J Clin Nutr 2012;96:1274-80.

11. Burt MG, Mangelsdorf BL, Srivastava D, et al. Acute effect of calcium citrate on serum calcium and cardiovascular function. $J$ Bone Miner Res 2013;28:412-8.

12. Bristow SM, Gamble GD, Stewart A, et al. Acute effects of calcium supplements on blood pressure and blood coagulation: secondary analysis of a randomised controlled trial in post-menopausal women. Br J Nutr 2015;114:1868-74.

13. Spence LA, Weaver CM. Calcium intake, vascular calcification, and vascular disease. Nutr Rev 2013;71:15-22.

14. Bhattacharya RK. Does widespread calcium supplementation pose cardiovascular risk? No: concerns are unwarranted. Am Fam Physician 2013;87:Online.

15. Lewis JR, Calver J, Zhu K, et al. Calcium supplementation and the risks of atherosclerotic vascular disease in older women: results of a 5-year RCT and a 4.5-year follow-up. J Bone Miner Res 2011;26:35-41.

16. Tomaschitz A, Pilz S, Ritz E, et al. Associations of plasma renin with 10-year cardiovascular mortality, sudden cardiac death, and death due to heart failure. Eur Heart J 2011;32:2642-9.

17. McCarty MF. Calcium supplementation, renin, and vascular risk. Osteoporos Int 2012;23:2733-4.

18. Lijnen P, Petrov V. Effect of oral calcium supplementation on intracellular calcium and plasma renin in men. $J$ Endocrinol 1995;146:421-9.

19. Petrov V, Lijnen P. Modification of intracellular calcium and plasma renin by dietary calcium in men. Am J Hypertens 1999;12:1217-24.

20. Rosanoff $A$, Weaver CM, Rude RK. Suboptimal magnesium status in the United States: are the health consequences underestimated? Nutr Rev 2012;70:153-64.

21. Zhang W, Iso $\mathrm{H}$, Ohira $\mathrm{T}$, et al. Associations of dietary magnesium intake with mortality from cardiovascular disease: the JACC study. Atherosclerosis 2012;221:587-95.

22. Chiuve SE, Korngold EC, Januzzi JL, et al. Plasma and dietary magnesium and risk of sudden cardiac death in women. Am J Clin Nutr 2011;93:253-60.

23. Misialek JR, Lopez FL, Lutsey PL, et al. Serum and dietary magnesium and incidence of atrial fibrillation in whites and in african Americans--atherosclerosis risk in communities (ARIC) study. Circ $J$ 2013;77:323-9.

24. Guasch-Ferré M, Bulló $M$, Estruch R, et al. Dietary magnesium intake is inversely associated with mortality in adults at high cardiovascular disease risk. J Nutr 2014;144:55-60.

25. Del Gobbo LC, Imamura F, Wu JH, et al. Circulating and dietary magnesium and risk of cardiovascular disease: a systematic review and meta-analysis of prospective studies. Am J Clin Nutr 2013:98:160-73.
26. Chiuve SE, Sun Q, Curhan GC, et al. Dietary and plasma magnesium and risk of coronary heart disease among women. J Am Heart Assoc 2013;2:e000114.

27. Qu X, Jin F, Hao Y, et al. Magnesium and the risk of cardiovascular events: a meta-analysis of prospective cohort studies. PLOS One 2013;8:e57720.

28. Joosten MM, Gansevoort RT, Mukamal KJ, et al. Urinary and plasma magnesium and risk of ischemic heart disease. Am J Clin Nutr 2013;97:1299-306

29. Yamori Y, Taguchi T, Mori $\mathrm{H}$, et al. Low cardiovascular risks in the middle aged males and females excreting greater 24-hour urinary taurine and magnesium in $41 \mathrm{WHO}-\mathrm{CARDIAC}$ study populations in the world. J Biomed Sci 2010;17:S21.

30. Kirii K, Iso H, Date $\mathrm{C}$, et al. Magnesium intake and risk of selfreported type 2 diabetes among Japanese. J Am Coll Nutr 2010;29:99-106.

31. Larsson SC, Orsini N, Wolk A. Dietary magnesium intake and risk of stroke: a meta-analysis of prospective studies. Am J Clin Nutr 2012;95:362-6.

32. Larsson SC, Virtamo J, Wolk A. Potassium, calcium, and magnesium intakes and risk of stroke in women. Am J Epidemiol 2011:174:35-43.

33. Evangelopoulos AA, Vallianou NG, Panagiotakos DB, et al. An inverse relationship between cumulating components of the metabolic syndrome and serum magnesium levels. Nutr Res 2008;28:659-63.

34. McKeown NM, Jacques PF, Zhang XL, et al. Dietary magnesium intake is related to metabolic syndrome in older Americans. Eur $J$ Nutr 2008;47:210-6.

35. He K, Song Y, Belin RJ, et al. Magnesium intake and the metabolic syndrome: epidemiologic evidence to date. J Cardiometab Syndr 2006;1:351-5.

36. Hruby A, Meigs JB, O'Donnell CJ, et al. Higher magnesium intake reduces risk of impaired glucose and insulin metabolism and progression from prediabetes to diabetes in middle-aged Americans. Diabetes Care 2014;37:419-27.

37. Hata A, Doi Y, Ninomiya T, et al. Magnesium intake decreases type 2 diabetes risk through the improvement of insulin resistance and inflammation: the Hisayama Study. Diabet Med 2013;30:1487-94

38. Oladapo $\mathrm{OO}$, Falase $\mathrm{AO}$. Congestive heart failure and ventricular arrhythmias in relation to serum magnesium. Afr J Med Med Sci 2000;29(3-4):265-8.

39. Joosten MM, Gansevoort RT, Mukamal KJ, et al. Urinary magnesium excretion and risk of hypertension: the prevention of renal and vascular end-stage disease study. Hypertension 2013;61:1161-7.

40. Massy ZA, Drüeke TB. Magnesium and outcomes in patients with chronic kidney disease: focus on vascular calcification, atherosclerosis and survival. Clin Kidney J 2012;5:i52-i61.

41. Lee SY, Hyun YY, Lee KB, et al. Low serum magnesium is associated with coronary artery calcification in a Korean population at low risk for cardiovascular disease. Nutr Metab Cardiovasc Dis 2015;25:1056-61.

42. Shechter M. Magnesium and cardiovascular system. Magnes Res 2010;23:60-72.

43. Shechter M, Merz CN, Paul-Labrador M, et al. Oral magnesium supplementation inhibits platelet-dependent thrombosis in patients with coronary artery disease. Am J Cardiol 1999;84:152-6.

44. Shechter M, Sharir M, Labrador MJ, et al. Oral magnesium therapy improves endothelial function in patients with coronary artery disease. Circulation 2000;102:2353-8.

45. Shechter $M$. The role of magnesium as antithrombotic therapy. Wien Med Wochenschr 2000;150(15-16):343-7.

46. Pokan R, Hofmann P, von Duvillard SP, et al. Oral magnesium therapy, exercise heart rate, exercise tolerance, and myocardial function in coronary artery disease patients. $\mathrm{Br} J$ Sports $\mathrm{Med}$ 2006;40:773-8.

47. Rosanoff $A$, Plesset MR. Oral magnesium supplements decrease high blood pressure (SBP>155 mmHg) in hypertensive subjects on anti-hypertensive medications: a targeted meta-analysis. Magnes Res 2013;26:93-9.

48. Resnick LM. Ionic basis of hypertension, insulin resistance, vascular disease, and related disorders. The mechanism of "syndrome X". Am $J$ Hypertens 1993;6:123S-34.

49. Resnick $L$. The cellular ionic basis of hypertension and allied clinical conditions. Prog Cardiovasc Dis 1999;42:1-22.

50. Grabarek Z. Insights into modulation of calcium signaling by magnesium in calmodulin, troponin $\mathrm{C}$ and related $\mathrm{EF}$-hand proteins. Biochim Biophys Acta 2011;1813:913-21.

51. McCarty MF. Magnesium may mediate the favorable impact of whole grains on insulin sensitivity by acting as a mild calcium antagonist. Med Hypotheses 2005;64:619-27. 
52. Malmendal A, Linse S, Evenäs J, et al. Battle for the EF-hands: magnesium-calcium interference in calmodulin. Biochemistry 1999;38:11844-50.

53. Iseri LT, French JH. Magnesium: nature's physiologic calcium blocker. Am Heart J 1984;108:188-93.

54. Mathew R, Altura BM. The role of magnesium in lung diseases: asthma, allergy and pulmonary hypertension. Magnes Trace Elem 1991;10(2-4):220-8.

55. Steurer G, Yang $P$, Rao V, et al. Acute myocardial infarction, reperfusion injury, and intravenous magnesium therapy: basic concepts and clinical implications. Am Heart J 1996;132:478-82.

56. Hruby A, O'Donnell CJ, Jacques PF, et al. Magnesium intake is inversely associated with coronary artery calcification: the Framingham Heart Study. JACC Cardiovasc Imaging 2014;7:59-69.

57. Seelig MS. The requirement of magnesium by the normal adult. summary and analysis of published data. Am J Clin Nutr 1964;14:242-90.

58. Lewis NM, Marcus MS, Behling AR, et al. Calcium supplements and milk: effects on acid-base balance and on retention of calcium, magnesium, and phosphorus. Am J Clin Nutr 1989;49:527-33.

59. Hoorn EJ, Zietse R. Disorders of calcium and magnesium balance: a physiology-based approach. Pediatr Nephrol 2013;28:1195-206.

60. Schlingmann KP, Waldegger S, Konrad M, et al. TRPM6 and TRPM7 Gatekeepers of human magnesium metabolism. Biochim Biophys Acta 2007;1772:813-21.

61. Hardwick LL, Jones MR, Brautbar N, et al. Magnesium absorption: mechanisms and the influence of vitamin $\mathrm{D}$, calcium and phosphate. J Nutr 1991;121:13-23.

62. Brink EJ, Beynen AC, Dekker PR, et al. Interaction of calcium and phosphate decreases ileal magnesium solubility and apparent magnesium absorption in rats. J Nutr 1992;122:580-6.

63. Uribarri J, Calvo MS. Hidden sources of phosphorus in the typical American diet: does it matter in nephrology? Semin Dia 2003;16:186-8.

64. Norman DA, Fordtran JS, Brinkley LJ, et al. Jejunal and ileal adaptation to alterations in dietary calcium: changes in calcium and magnesium absorption and pathogenetic role of parathyroid hormone and 1,25-dihydroxyvitamin D. J Clin Invest 1981;67:1599-603.

65. Dimke H, Hoenderop JG, Bindels RJ. Molecular basis of epithelial $\mathrm{Ca} 2+$ and $\mathrm{Mg} 2+$ transport: insights from the TRP channel family. $J$ Physiol 2011;589(Pt 7):1535-42.

66. Krejs GJ, Nicar MJ, Zerwekh JE, et al. Effect of

1,25-dihydroxyvitamin D3 on calcium and magnesium absorption in the healthy human jejunum and ileum. Am J Med 1983;75:973-6.

67. Schmulen AC, Lerman M, Pak CY, et al. Effect of 1,25-(OH)2D3 on jejunal absorption of magnesium in patients with chronic renal disease. Am J Physiol 1980;238:G349-G352.

68. Krejs GJ, Nicar MJ, Zerwekh JE, et al. Effect of 1,25-dihydroxyvitamin D3 on calcium and magnesium absorption in the healthy human jejunum and ileum. Am J Med 1983;75:973-6.

69. Hodgkinson A, Marshall DH, Nordin BE. Vitamin D and magnesium absorption in man. Clin Sci 1979;57:121-3.

70. Karbach U, Ewe K. Calcium and magnesium transport and influence of 1,25-dihydroxyvitamin D3. In vivo perfusion study at the colon of the rat. Digestion 1987;37:35-42.

71. Levine BS, Brautbar N, Walling MW, et al. Effects of vitamin D and diet magnesium on magnesium metabolism. Am J Physiol 1980;239:E515-E523.

72. Seelig MS. Increased need for magnesium with the use of combined oestrogen and calcium for osteoporosis treatment. Magnes Res 1990;3:197-215.

73. Durlach J. Recommended dietary amounts of magnesium: mg RDA. Magnes Res 1989;2:195-203.

74. Rude RK, Gruber HE. Magnesium deficiency and osteoporosis: animal and human observations. J Nutr Biochem 2004;15:710-6.

75. Aydin H, Deyneli O, Yavuz D, et al. Short-term oral magnesium supplementation suppresses bone turnover in postmenopausal osteoporotic women. Biol Trace Elem Res 2010;133:136-43.

76. Ryder KM, Shorr RI, Bush AJ, et al. Magnesium intake from food and supplements is associated with bone mineral density in healthy older white subjects. J Am Geriatr Soc 2005;53:1875-80.

77. Dai Q, Shu XO, Deng X, et al. Modifying effect of calcium/ magnesium intake ratio and mortality: a population-based cohort study. BMJ Open 2013;3:e002111. 